\title{
PRICING AND INVENTORY CONTROL DECISIONS IN THE STOCHASTIC HYBRID PRODUCTION SYSTEMS WITH MULTIPLE RECOVERY OPTIONS
}

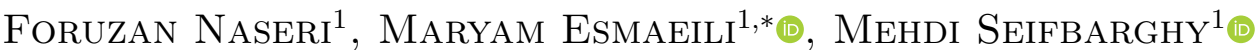 \\ AND TAHEREH HEYDARI ${ }^{2}$
}

\begin{abstract}
Although pricing and inventory control are crucial decisions in each production system, these decisions are usually investigated separately. This paper considers pricing and inventory control decisions simultaneously in a hybrid production system. The hybrid production system has two recovery options, remanufacturing and refurbishing sites. The demand follows Poisson distribution, which depends on the sale price of each product. Returned products arrive according to a Poisson process. Each returned product can be remanufactured, refurbished, or disposed. The time to manufacturing, refurbishing, and remanufacturing a product also follows an exponential distribution. By modeling the system as a Markov chain, the long-run expected profit function is obtained in terms of the disposedown-to level of returned products and the order-up-to level and the sale price of serviceable products. A three-dimensional state space of the Markov Chain dependent to the sale price is developed considering pricing and inventory control decisions simultaneously with remanufacturing and refurbishing returned products. Since the model is a mixed integer nonlinear programming and known as complex models, the Artificial Bee Colony (ABC) algorithm, simulation and complete search method are used to solve the problem. The results show that by increasing the purchase price of the returned products, the amount of returned products will increase. If the refurbishing cost of the returned products is high or the disposal cost is low, less inventory should be kept in the system with a high price of serviceable products. If the lost sale cost is high, the more inventory should be maintained. Moreover, by decreasing the price elasticity of demand, the customer's demand increases, and then more inventory should be maintained in the system.
\end{abstract}

Mathematics Subject Classification. 91G30.

Received April 16, 2020. Accepted July 29, 2021.

\section{INTRODUCTION}

Reverse logistics is the process of planning, implementing, and controlling the efficient, cost effective flow of raw materials, in-process inventory, finished goods and related information from the point of consumption to

\footnotetext{
Keywords. Hybrid production system, pricing, ABC algorithm, base stock.

1 Department of Industrial Engineering, Faculty of Engineering, Alzahra University, Tehran, Iran.

2 Department of Industrial Engineering, Faculty of Engineering, Payame Noor University (PNU), P.O. Box 19395-3697, Tehran, Iran.

* Corresponding author: esmaeili_m@alzahra.ac.ir
} 
the point of origin to recapture value or proper disposal [9]. Reverse logistics has gained increasing attention as a profitable and sustainable strategy in the industrial world [22]. Moreover, reverse logistics may be motivated by economic, legislative, or environmental reasons [10]. Reverse logistics activities include collecting, inspecting, isolating, reprocessing, recovery, and redistributing [9]. There are five recovery options: repairing, refurbishing, remanufacturing, cannibalizing, and recycling. Repairing processes involve replacing or fixing defective parts. Refurbishing processes bring the returned products up to a specified quality by replacing the old parts and modules with technologically superior ones. In Remanufacturing processes, the returned products are entirely recovered, and their qualities after remanufacturing are as good as that of a new product. Cannibalization recovers the parts of the returned products, and these parts are reused in repairing, refurbishing or remanufacturing of other products. In recycling processes, the returned products are grinded, and their materials can be used as raw material, such as paper pulps and glasses [24]. Systems, which include both manufacturing and recovery activities, are called hybrid production systems [31]. There are many papers on the inventory control of the hybrid production systems. The inventory control of the production systems is categorized into deterministic and stochastic models. The stochastic models are also divided into periodic review models and continuous review models [21]. In the following, at first, the periodic review models and then the continuous review models are reviewed.

As can be understood from the literature of inventory control, the demand does not change throughout the product life cycle. The changes could be resulted from the selling price, reliability, product quality, or marketing green expenditure $[18,20]$. In the periodic review models, also the common assumption is that the demand and the amount of the return products are independent and usually follow the Poisson distribution. For example, Simpson [21] considered a system with zero manufacturing and remanufacturing lead times in which the returns are held in a separate buffer until they are remanufactured or disposed of. He demonstrated that by considering the zero manufacturing and remanufacturing lead times, a triple policy including the repair-up-to-level, the purchase-up-to-level, and the scrape-down-to-level is optimal. Inderfurth [14] assumed identical manufacturing and remanufacturing lead times. He demonstrated that the optimal policy for equal lead times is the same as that of the zero lead times. DeCroix [8] extended the given model by Inderfurth [14] to a multi-stage system in which the return products are remanufactured, and then enter a sequential manufacturing process. Based on the model given by Inderfurth [14], Kiesmuller [17] considered a manufacturing and remanufacturing system with fixed manufacturing and remanufacturing lead times. She demonstrated that manufacturing and remanufacturing lead times are useful in determining the inventory position. Later, Ahiska and King [1] considered a manufacturingremanufacturing system with fixed manufacturing and remanufacturing lead times. They found three states for the lead time; same manufacturing and remanufacturing lead times, manufacturing lead time larger than remanufacturing lead time, and remanufacturing lead time larger than manufacturing lead time. The obtained results showed that the optimal policy did not change regarding different lead times and equal costs. The lead time also affected the inventory position. In contrary to the first group of paper, Ahiska and King [2] studied the changes in demand and returned rates over the life cycle of the product considering the same manufacturing and remanufacturing lead times. Also, Benedito and Corominas [6] considered a manufacturing-remanufacturing system in which the return rate of each period was dependent on the demand for the previous periods. They obtained the optimal manufacturing policy in each period by modeling the system as a Markov chain. Later, Zolfagharinia et al. [32] supposed that the return rate depends on the demand, and demand rates were different over the life cycle of the product. They obtained the order-up-to level for each phase of the product life cycle.

The continuous review inventory control system with return was proposed first by Heyman [13]. He assumed zero lead time and linear costs for manufacturing and remanufacturing to determine the optimal disposal level. Muckstadt and Isaac [19] studied a similar model with positive lead times without considering the disposal option. Several researchers examined the effect of different inventory control policies on system costs. Van der Laan et al. [26] modeled remanufacturing facilities as an $M / M / C / C+N$ queue with $C$ parallel servers. They developed $\left(s_{p}, Q_{p}, N\right)$ policy in which $s_{p}$ is reordering point, $Q_{p}$ represents the amount of order and every return is disposed of whenever the number of products waiting to be repaired is equal to $N$. Also, Van der Laan et al. [27] developed this policy with $\left(s_{p}, Q_{p}, s_{d}, N\right)$ policy in which the returns are disposed of whenever their 
stock level is higher than $s_{d}$. Later, Van der Laan and Salomon [25] introduced two inventory control policies called pull-disposal and push-disposal in the hybrid production system.

Moreover, Takahashi et al. [23] offered an adaptive pull policy to control the manufacturing and remanufacturing rates in the manufacturing-remanufacturing system. In addition to considering different inventory control policies, Van der Laan et al. [28] studied the effect of lead time length and lead time variability on the expected cost of the system. The results showed that for push and pull policies, the manufacturing lead time compared with the remanufacturing lead time has a higher significant effect on the expected cost. Inderfurth and van der Laan [16] also demonstrated that the optimal policy structure was considerably complicated if manufacturing and remanufacturing lead times were different.

Similar quality for manufacturing and remanufacturing products and performing manufacturing and remanufacturing operations by two servers are common assumptions of the previous group of researches. However, Inderfurth [15] assumed that new manufacturing products have higher quality than remanufacturing products, and the new ones can be substituted with the remanufactured products. This policy was called the downward substitution policy. Similar to Inderfurth [15], Bayındır et al. [4] considered the downward substitution policy with exponential manufacturing and remanufacturing lead times. Also, Flapper et al. [10] studied a manufacturing-remanufacturing system in which the same single server performed manufacturing and remanufacturing operations. The server was able to perform just one operation at any time. Through modeling the system as a Markov decision process, the optimal manufacturing-remanufacturing policy was determined.

There are a few types of researches on pricing in manufacturing-remanufacturing systems with Poisson's demand and return. For instance, Xiong and Li [29] considered a remanufacturing system in which the return rate of used products depended on price. The manufacturer remanufactures the returned products in one period and then sells them in the next period of time. The interaction between the manufacturer and the retailer is modeled as the manufacturer -Stackelberg. The demand for each channel is a function of the selling prices and the green level. They determined the optimal product quality, refund price, selling price, and wholesale price of first and second periods by maximizing the profits of the manufacturer and retailer. Giri et al. [12] addressed a two-period closed-loop supply chain. In another research, Xiong et al. [30] proposed the dynamic pricing policy for the cores. Later, Gao et al. [11] considered a manufacturing-remanufacturing system in which demand followed Poisson distribution with a price-dependent demand rate. They obtain the base stock inventory level and the sale price of products so that the expected profits are maximized over an infinite planning horizon. In the addressed researches, the given models are considered as a continuous time Markov chain process.

A significant shortcoming of all these models is that they only regard one recovery option without considering other ways that a returned product can be used. For example, a mobile phone may be refurbished and sold at a lower price than new mobile phones or its parts may be separated and used in the production of other mobile phones. Each of these recovery options has different costs and recovery times, and also the revenue obtained from each of the recovery options is different. Therefore, in inventory management of returned products, the stock level of different recovery options and the stock level of returned products should be specified. In this paper, a hybrid production system with two recovery options is considered; refurbishing and remanufacturing. By remanufacturing, the returned products are entirely recovered, and their quality after remanufacturing is assumed to be as good as that of a new product [24]. The returned products arrive according to a Poisson process. Each returned product can be remanufactured, refurbished, or disposed of. The returned products are disposed of when the inventory is higher than a certain level regarding the limited capacity [13, 23, 25-27]. The time to manufacturing, refurbishing, and remanufacturing a product follows an exponential distribution. There is one stock/inventory point for the returned product, and there are two stock/inventory points for two serviceable products. The first serviceable inventory point is replenished by refurbishing, and the second serviceable inventory point is replenished by remanufacturing and manufacturing. The two serviceable inventory points are replenished according to the base stock policy. The demand for each serviceable product arrives according to a nonhomogeneous Poisson process with a price-dependent arrival rate at that time. The demands that cannot be satisfied are lost. By modeling the system as a Markov chain, the long-run expected profit function is obtained in terms of the dispose-down-to level of returned products and the order-up-to level and 


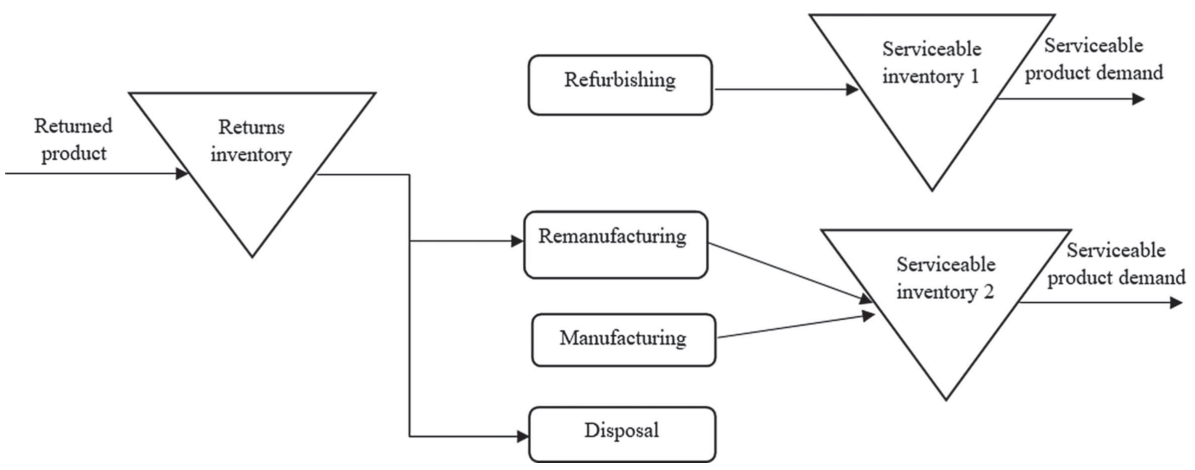

FiguRE 1. Schematic representation of the hybrid production system with two recovery options.

the sale price of serviceable products A three-dimensional state space of the Markov Chain dependent to the sale price is developed considering pricing and inventory control decisions simultaneously with remanufacturing and refurbishing returned products. Due to the complexity of the model (which is a mixed integer nonlinear programming) [7], the Artificial Bee Colony (ABC) algorithm and the complete search method are used in order to solve the complex problem. Thus, the contribution of the paper is as follows:

- Considering a hybrid production system with two recovery options (i.e. remanufacturing and refurbishing).

- Considering the price-dependent demand rate.

- Investigating pricing and inventory control decisions simultaneously.

- Considering a Markov chain with sale price dependent state space.

The questions have to be answered as follows:

- When should the returned products are maintained as inventory, and when are disposed of?

- What is the base stock level of the serviceable products?

- What is the sale price of the serviceable products?

The remainder of this paper is organized as follows. In Section 2, description and modeling of the system are given. In Section 3, the ABC algorithm is explained in detail. In Section 4, the results of the numerical examples are discussed. Finally, in Section 5, the conclusion and future research directions are presented.

\section{System DESCRIPTION AND MODELING}

In this paper, a hybrid production system is considered (Fig. 1). This system includes a refurbishment process, a manufacturing process, a remanufacturing process, and three inventory points to hold returned products, serviceable products 1 and serviceable products 2 . The two serviceable inventory are replenished according to the base stock policy. Returned products arrive according to a Poisson process. If the inventory of returned products is lower than a certain level, the returned products are stored otherwise, they are disposed. Two recovery processes are considered: refurbishing and remanufacturing. The refurbished products are maintained in the serviceable inventory 1 and are sold at the price of $p_{1}$. Manufactured and remanufactured products are assumed to have the same qualities. They are maintained in the serviceable inventory 2 and are sold at the price of $p_{2}$. Real examples of the hybrid production system could be returned copiers and mobile phones. Some parts are substituted (refurbishing) or are taken apart entirely, and some other parts are used for the production of new ones (i.e. remanufacturing). Decision variables, parameters, assumptions, and formulation of the problem are described in Sections 2.1, 2.2, 2.3, and 2.4, respectively. 


\subsection{Variables}

$R$ : Dispose-down-to level of returned products.

$S_{i}$ : Order-up-to level of serviceable product $i ;(i=1,2)$.

$p_{i}$ : Unit sale price of serviceable product $i ;(i=1,2)(\$ /$ unit $)$.

\subsection{Parameters}

$r$ : Mean return rate (unit/time).

$\lambda_{i}$ : Mean demand rate of serviceable product $i ;(i=1,2)$ (unit/time).

$\mu_{1}, \mu_{2}, \mu_{3}$ : Mean refurbishing, remanufacturing and manufacturing rate, respectively (unit/time).

$I_{1}, I_{2}, I_{3}$ : Inventory level of returned products, serviceable product 1 and serviceable product 2 , respectively.

$p_{3}$ : Unit purchase price of returned products (\$/unit).

$h_{1}, h_{2}, h_{3}$ : Unit holding cost of returned product, serviceable product 1 and serviceable product 2 per unit time, respectively $(\$ /$ (unit $\times$ unit $)$ ).

$c_{1}, c_{2}, c_{3}$ : Unit refurbishing, remanufacturing and manufacturing cost, respectively ( $\$ /$ unit).

$c_{d}$ : Unit disposing cost (\$/unit).

$c_{n i}$ : Unit lost sale cost of serviceable product $i(i=1,2)(\$ /$ unit).

\subsection{Assumptions}

Assumptions of the paper are as follows:

(1) The return of used products to the system follows the Poisson distribution with rate $r[10,11,29]$.

(2) The demand for serviceable product $i$ follows Poisson distribution with rate $\lambda_{i}[5,10,15,26] . \lambda_{i}$ is a linear function of price of product $i \lambda_{i}=\alpha_{i}-\beta_{i} p_{i}(i=1,2)$ [28].

(3) The lead time of refurbishment, remanufacturing, and manufacturing processes follow the exponential distribution with rate $1 / \mu_{1}, 1 / \mu_{2}$, and $1 / \mu_{3}$, respectively $[4,10,23]$.

(4) The unsatisfied demands are lost $[4,23]$.

\subsection{Formulation of the problem}

The inventory level of returned products $\left(I_{r}\right)$, serviceable products $1\left(I_{1}\right)$ and serviceable products $2\left(I_{2}\right)$ are modeled as a three-dimensional Markov chain with state space $M=\left\{\left(I_{r}, I_{2}, I_{3}\right) \mid I_{r} \in\{0,1,2, \ldots, R\}, I_{1} \in\right.$ $\left.\left\{0,1,2, \ldots, S_{1}\right\}, I_{2} \in\left\{0,1,2, \ldots, S_{2}\right\}\right\}$ for given $\left(R, S_{1}, S_{2}\right)$ policy. The $\left(R, S_{1}, S_{2}\right)$ policy is defined as follows. If the return inventory position is equal to $R$ or higher, the returns will be disposed. If the serviceable product 1 inventory position drops to or below $S_{1}$, then refurbishment facility will be opened until the serviceable product 1 inventory position reaches $S_{1}$. If the serviceable product 1 drops to or below $S_{2}$, then manufacturing and remanufacturing facilities will be opened until the serviceable product 1 inventory position reaches $S_{2}$. Changes in system states occur by one of the following events:

- The arrival of the returned product and storing it, the inventory system state will be changed from $(i, j, k)$ to $(i+1, j, k)$ with rate $r$.

- The occurrence of the demand for serviceable products 1 , the inventory system state will be changed from $(i, j, k)$ to $(i \cdot j-1, k)$ with rate $\lambda_{1}$.

- The occurrence of the demand for serviceable products 2 , the inventory system state will be changed from $(i, j, k)$ to $(i, j, k-1)$ with rate $\lambda_{2}$.

- The completion of the refurbished product, the inventory system state will be changed from $(i, j, k)$ to $(i-1, j+1, k)$ with rate $\mu_{1}$.

- The completion of the remanufactured product, the inventory system state will be changed from $(i, j, k)$ to $(i-1, j, k+1)$ with rate $\mu_{2}$.

- The completion of the manufactured product, the inventory system state, will be changed from $(i, j, k)$ to $(i, j, k+1)$ with rate $\mu_{3}$. 
For each $\left(R, S_{1}, S_{2}\right)$ policy, Markov chain rate matrix $(Q)$, based on the listed states, is given as in Appendix A. Using the rate matrix, the normalization and balance equations are expressed as follows:

$$
\begin{aligned}
\pi Q & =0 \\
\pi e & =1
\end{aligned}
$$

where $\pi$, and $e$ are the steady state probability and elementary matrices. By solving (2.1) and (2.2), the steadystate probabilities are calculated. The steady-state probabilities, $p i_{i j} j$ is interpreted as the fraction of time that return product inventory is $i$, serviceable product inventory 1 is $j$ and serviceable product inventory 2 is $k$. Therefore, the overall system policy is determined by $\left(R, S_{1}, S_{2}, p_{1}, p_{2}\right)$ in which the first three parameters (i.e. the probabilities) are inventory control policy parameters, and the remained two parameters represent the sale prices of products 1 and 2, respectively. The demand for serviceable product 1 is fulfilled if the serviceable inventory is available, and otherwise, is lost. The long-run expected income of serviceable products 1 and 2 for a given $\left(R, S_{1}, S_{2}, p_{1}, p_{2}\right)$ policy is written as follows:

The Long-run Expected Income of Serviceable Products = The Long-run Expected Income of Serviceable Product $\mathbf{1}+$ The Long-run Expected Income of Serviceable Product 2. Equation (2.3) gives the mathematical form of this equality.

$$
\text { Income }\left(R, S_{1}, S_{2}, p_{1}, p_{2}\right)=p_{1} \lambda_{1}\left(1-\sum_{i=0}^{R} \sum_{k=0}^{s_{2}} \pi_{i 0 k}\right)+p_{2} \lambda_{2}\left(1-\sum_{i=0}^{R} \sum_{j=0}^{s_{1}} \pi_{i j 0}\right) \text {. }
$$

In the long term, the fraction of time that $i$ units of the return products, $j$ units of the serviceable products 1 and $k$ units of the serviceable product 2 that are held in the inventory is represented by $\pi_{i j k}$. For each unit held in the inventory, the unit holding cost is considered per time unit. Therefore, the long-run expected holding cost for given $\left(R, S_{1}, S_{2}, p_{1}, p_{2}\right)$ policy is as follows:

The Long-run Expected Holding Cost $=$ The Long-run Expected Holding Cost of Returned Products + The Long-run Expected Holding Cost of Serviceable Products 1 + The Long-run Expected Holding Cost of Serviceable Products 2. Equation (2.4) gives the mathematical form of this equality.

$$
h\left(R, S_{1}, S_{2}, p_{1}, p_{2}\right)=h_{1} \sum_{i=1}^{R} \sum_{j=0}^{s_{1}} \sum_{k=0}^{s_{2}} i \pi_{i j k}+h_{2} \sum_{i=0}^{R} \sum_{j=1}^{s_{1}} \sum_{k=0}^{s_{2}} j \pi_{i j k}+h_{3} \sum_{i=0}^{R} \sum_{j=0}^{s_{1}} \sum_{k=1}^{s_{2}} k \pi_{i j k} .
$$

Manufacturing, remanufacturing, and refurbishing activities are performed when the corresponding pure inventory levels are lower than the corresponding order-up-to levels. Therefore, in order to obtain manufacturing, remanufacturing and refurbishing costs in the long term, it is necessary to multiply the fraction of the time that system carries out for each of these operations by the corresponding production rate and by the production cost. The long-run expected recycling process cost for given $\left(R, S_{1}, S_{2}, p_{1}, p_{2}\right)$ policy is given as follows:

The Long-run Expected Recycling Process Cost = The Long-run Expected Refurbishing Cost + The Long-run Expected Remanufacturing Cost + The Long-run Expected Manufacturing Cost. Equation (2.5) gives the mathematical form of this equality

$$
\begin{aligned}
\mathrm{CP}\left(R, S_{1}, S_{2}, p_{1}, p_{2}\right)= & c_{1} \mu_{1}\left(1-\sum_{i=0}^{R} \sum_{k=0}^{s_{2}} \pi_{i s_{1} k}\right)+c_{2} \mu_{2}\left(1-\sum_{i=0}^{R} \sum_{j=0}^{s_{1}} \pi_{i j s_{2}}-\sum_{j=0}^{s_{1}} \sum_{k=0, \neq s_{2}}^{s_{2}} \pi_{0 j k}\right) \\
& +c_{3} \mu_{3}\left(1-\sum_{i=0}^{R} \sum_{j=0}^{s_{1}} \pi_{i j s_{2}}\right) .
\end{aligned}
$$


Regarding $\left(R, S_{1}, S_{2}, p_{1}, p_{2}\right)$ policy, the return products are disposed when $I_{r}=R$. Therefore, the long-run expected disposal cost is calculated as follows:

$$
\mathrm{CD}\left(R, S_{1}, S_{2}, p_{1}, p_{2}\right)=c_{d} r \sum_{j=0}^{s_{1}} \sum_{k=0}^{s_{2}} \pi_{R j k} .
$$

$\sum_{j=0}^{S_{1}} \sum_{k=0}^{S_{2}} \pi_{R j k}$ represents the fraction of the time in which return products are disposed. In the long term, the fraction of time that $i$ units of the return products, $j$ units of the serviceable products 1 and $k$ units of the serviceable products 2 that are held in the inventory is $\pi_{i j k}$. For each shortage unit in the inventory, the unit lost sale cost is considered per time unit. Therefore, the long-run expected lost sale cost for given $\left(R, S_{1}, S_{2}, p_{1}, p_{2}\right)$ policy is as follows:

The Long-run Expected Lost Sale Cost $=$ The Long-run Expected Lost Sale Cost of Serviceable Products 1 + The Long-run Expected Lost Sale Cost of Serviceable Products 2. Equation (2.7) gives the mathematical form of this equality

$$
\mathrm{CL}\left(R, S_{1}, S_{2}, p_{1}, p_{2}\right)=c_{n_{1}} \lambda_{1} \sum_{i=0}^{R} \sum_{k=0}^{s_{2}} \pi_{i 0 k}+c_{n_{2}} \lambda_{2} \sum_{i=0}^{R} \sum_{j=0}^{s_{1}} \pi_{i j 0} .
$$

Finally, when the price of each return product unit is multiplied by the number of the returned products, the cost of buying the returned product can be given as in equation (2.8):

$$
\mathrm{CB}=p_{3} r .
$$

In order to obtain the optimal $\left(R, S_{1}, S_{2}, p_{1}, p_{2}\right)$, maximizing the long-run expected profit, the following model (2.9)-(2.14) should be optimized:

$$
\begin{aligned}
& \max \operatorname{Pofit}\left(R, S_{1}, S_{2}, p_{1}, p_{2}\right)=\operatorname{Income}\left(R, S_{1}, S_{2}, p_{1}, p_{2}\right)-H\left(R, S_{1}, S_{2}, p_{1}, p_{2}\right)-\operatorname{CP}\left(R, S_{1}, S_{2}, p_{1}, p_{2}\right) \\
& \qquad-\operatorname{CD}\left(R, S_{1}, S_{2}, p_{1}, p_{2}\right)-\operatorname{CL}\left(R, S_{1}, S_{2}, p_{1}, p_{2}\right)-\mathrm{CB} \\
& \text { s.t. } \\
& \quad p_{2} \geq p_{1} \\
& \quad p_{1} \geq c_{1}+p_{3} \\
& \quad p_{2} \geq c_{2}+p_{3} \\
& \quad R, S_{1}, S_{2} \text { are integer } \\
& \quad p_{1}, p_{2} \geq 0
\end{aligned}
$$

where $R, H, \mathrm{CD}$ and $\mathrm{CB}$ are expressed by $(2.3)-(2.8)$.

The objective function, equation (2.9) maximizes the long-run expected profit. The details of the objective function, including the long-run expected income and the long-run expected costs, were described in (2.3)-(2.8). Constraint (2.10) guarantees that the price of the serviceable product 1 is lower than that of serviceable product 2. Constraints (2.11) and (2.12) guarantee that the price of each serviceable product are higher than its recovery and purchase costs. Constraint (2.13) ensures that $R, S_{1}$, and $S_{2}$ are integer variables. Constraint (2.14) ensures that the price of the serviceable product 1 and 2 should be non-negative.

\section{ABC Algorithm}

Since the given problem is of mixed integer nonlinear programming, and is complex to solve using the traditional optimization methods, we use complete search and $\mathrm{ABC}$ algorithm in order to solve them considering the inventory control parameters (i.e. three discrete decision variables), and the selling price of products (i.e. 
two continuous decision variables) [7]. The excellent performance of the ABC algorithm comparing to other algorithms such as genetic algorithm (GA) and particle swarm optimization (PSO), motivates using ABC algorithm which is based on the foraging behavior of honey bee. The colony of artificial bees consists of three kinds of bees: employed bee, onlooker bee, and scout bee. Each employed bee searches the food around the food source and comes back to hive. These bees exchange information with onlooker bees. The probability of choosing a more beneficial food source increases by onlooker bees. The food source that has been abandoned is replaced with a new food source which has been discovered by the scout bee. ABC algorithm consists of four phases: initialization phase, employed bee phase, onlooker bee phase, and scout bee phase. After the initialization phase, the other three phases of $\mathrm{ABC}$ are implemented in a loop until the termination condition is met [3]. In the present study, the maximum cycle number has been adopted. ABC phases are summarized as follows:

\subsection{Initialization phase}

In the $\mathrm{ABC}$ algorithm, the position of a food source and the nectar amount of a food source present a possible solution and the fitness of the associated solution, respectively. In this algorithm, the number of employed/onlooker bees are equivalent to the number of solutions in the population (SN). In the initialization phase, a population of random solutions is generated. A random population of the solution is generated as follows [3]:

$$
X_{i j}=X_{j}^{\min }+(0,1) \times\left(X_{j}^{\max }-X_{j}^{\min }\right)
$$

where $j \in\{1,2, \ldots, D\} . D$ is the number of the problem parameter.

\subsection{Employed bee phase}

In this phase, first, a neighboring food source in the vicinity of the selected food source is generated by each employed bee. The new food source is generated by using the following equation [3]:

$$
\vartheta_{i j}=X_{i j}+\varphi_{i j}\left(X_{i j}-X_{k j}\right)
$$

where $k \in\{1,2, \ldots, D\}$ and $j \in\{1,2, \ldots, D\} . \varphi_{i j}$ represents a random number between $[-1,1] . k$ has to differ from $i$.

Second, a fitness value is assigned to the solution $\vartheta_{i j}$ as follows (for a minimization problem):

$$
\text { fitness }_{i}= \begin{cases}\frac{1}{1+f_{i}} & f_{i} \geq 0 \\ 1+\left|f_{i}\right| & f_{i}<0\end{cases}
$$

If the fitness of $\vartheta_{i j}$ is higher than $X_{i j} \vartheta_{i j}$ will replace $X_{i j}$. Then $\vartheta_{i j}$ become a new member of the population. Otherwise, $\vartheta_{i j}$ retained.

\subsection{Onlooker bee phase}

In this phase, each onlooker bee selects a food source depending on the probability value $P_{i}$. The value of $P_{i}$ is calculated by using equation (3.4) [3]:

$$
p_{i}=\frac{\text { fitness }_{i}}{\sum_{n=1}^{\mathrm{SN}} \text { fitness }_{n}} .
$$

If the fitness of $\vartheta_{i j}$ is higher than $X_{i j}, \vartheta_{i j}$ will be replaced with $X_{i j}$. Then $\vartheta_{i j}$ become a new member of the population; otherwise, $\vartheta_{i j}$ remains. 
TABLE 1. Information of each numerical example.

\begin{tabular}{lllllllllllllll}
\hline \hline Example & $r$ & $\mu_{1}$ & $\mu_{2}$ & $\mu_{3}$ & $P_{3}$ & $h_{1}$ & $h_{2}$ & $h_{3}$ & $c_{1}$ & $c_{2}$ & $c_{3}$ & $c_{d}$ & $c_{n 1}$ & $c_{n 2}$ \\
\hline 1 & 15 & 20 & 15 & 10 & 5 & 5 & 10 & 15 & 5 & 2 & 8 & 30 & 60 & 30 \\
2 & 10 & 15 & 10 & 10 & 5 & 3 & 8 & 12 & 10 & 6 & 15 & 30 & 100 & 50 \\
3 & 10 & 15 & 15 & 20 & 3 & 4 & 6 & 10 & 7 & 5 & 10 & 20 & 50 & 30 \\
\hline
\end{tabular}

\begin{tabular}{|l|l|l|l|l|}
\hline $\mathrm{a}_{1}$ & $\mathrm{a}_{2}$ & $\mathrm{a}_{3}$ & $\mathrm{a}_{4}$ & $\mathrm{a}_{5}$ \\
\hline
\end{tabular}

FIGURE 2. The representation of the solution.

\subsection{Scout bee phase}

In the $\mathrm{ABC}$ algorithm, if the position does not improve after several cycles, that food source is abandoned. The predetermined number of cycles is called "limit". The abandoned food source is replaced with a new food source that has been discovered by the scout bee. The new food source is defined as follows [3]:

$$
X_{i}^{j}=X_{\min }^{j}+\operatorname{rand}(0,1)\left(X_{\max }^{j}-X_{\min }^{j}\right) .
$$

\section{Computation Results}

In this section, numerical examples and sensitivity analysis of the critical parameters is investigated.

\subsection{Numerical examples}

In order to evaluate the proposed model, three numerical examples for different values of $\left(R, S_{1}, S_{2}\right)$ are solved. The two methods, including the complete search method and ABC metaheuristic algorithm, will be compared in terms of their solution and runtime. Moreover, the ABC algorithm and simulation with Enterprise dynamics (ED) software have been used to solve large scale examples. The data of three numerical examples are shown in Table 1 [23].

Moreover, the demand rates of the serviceable products 1 and 2 for each example is respectively as follows:

$$
\begin{array}{llllll}
\lambda_{1}(p)=20-0.3 p_{1} & \text { and } \quad \lambda_{2}(p)=20-0.2 p_{2}, & \text { where } & p_{1} \in[1,66] & \text { and } & p_{2} \in[1,99] \\
\lambda_{1}(p)=15-0.3 p_{1} & \text { and } \quad \lambda_{2}(p)=15-0.2 p_{2}, & \text { where } & p_{1} \in[1,49] & \text { and } & p_{2} \in[1,74] \\
\lambda_{1}(p)=15-0.3 p_{1} & \text { and } \quad \lambda_{2}(p)=20-0.2 p_{2}, & \text { where } & p_{1} \in[1,49] & \text { and } & p_{2} \in[1,99] .
\end{array}
$$

Regarding the complexity of model [4,23], the used methods, complete search method and ABC metaheuristic algorithm are compared in terms of their solution and runtime. For different values of $\left(R, S_{1}, S_{2}\right), p_{1}$, and $p_{2}$ are obtained by Hook and Jeeves method [24]. The combination of $\left(R, S_{1}, S_{2}, p_{1}, p_{2}\right)$ that maximizes the objective function is the optimal solution $[4,23]$. When the state space increases; however, the required time to solve the problem by this method also increases. The ABC algorithm for solving large scale instances of the problems is also used. The following solution structure is used in order to solve the problem by ABC algorithm (Fig. 2).

$a_{1}-a_{5}$ denote $R, S_{1}, S_{2}, p_{1}$ and $p_{2}$, respectively.

Three parameters are chosen for the level of the ABC algorithm parameters; maximum cycle number (MSN), solution number $(\mathrm{SN})$ and limit. After performing elementary experiments and selecting the suitable levels for each parameter (Tab. 2), the best parameter combination is found by Taguchi method (Tab. 3).

Based on the parameters in Table 1, three numerical examples with different values of $\left(R, S_{1}, S_{2}\right)$ are run by the ABC algorithm and the complete search method. Two methods are coded in MATLAB on a computer with 
TABLE 2. Selected level for parameters of ABC.

\begin{tabular}{lllll}
\hline \hline Parameter & Level 1 & Level 2 & Level 3 & Level 4 \\
\hline Number of solutions & 50 & 100 & 150 & 200 \\
Number of cycles & 50 & 100 & 150 & 200 \\
Limit & 40 & 60 & 80 & 100 \\
\hline
\end{tabular}

TABLE 3. The results of parameters tuning using Taguchi method.

\begin{tabular}{lll}
\hline \hline Number of solutions & Number of cycles & Limit \\
\hline 50 & 100 & 40 \\
\hline
\end{tabular}

$8 \mathrm{~GB}$ RAM and core i7 with a $2.9 \mathrm{GHz}$ processor. The obtained results for numerical examples 1,2 , and 3 are shown in Tables 4, 5, and 6 in sequence. Moreover, the mean, standard deviation (SD), and Error of the long-run expected profit are shown in Tables $4-6$. The run time will considerably increase by the complete search method by increasing the problem's state space. Therefore, the ABC algorithm and simulation with Enterprise dynamics (ED)software have been used to solve large scale examples. Please note in Tables 4-6 (\% Error) represents the percentage error between numerical search and the $\mathrm{ABC}$ algorithm for small scale examples, and (\% Error) represents the percentage error between simulation and the ABC algorithm for large scale examples. We first drew the software model for the ED simulation method and then defined all the atom's parameters (Fig. 3). By adding the initialize atoms, we do the formulation needed to calculate the objective function. The simulation runs 250 times, and each run, the pi, and si are executed randomly within the defined range, and the value of the objective function is calculated (Tabs. 4-6). Results show that for small scale examples, control parameters $D$, $S_{1}$ and $S_{2}$, and the sale price of each product $p_{1}$ and $p_{2}$ are equal when using the complete research method and $\mathrm{ABC}$ algorithm. Moreover, largescale examples obtained results are approximately the same as the simulation and the $\mathrm{ABC}$ algorithm.

\subsection{Sensitivity analysis}

The effects of return, remanufacturing, and refurbishing rate changes on the expected profit function, prices, and the inventory management system are studied.

Refurbishing rate effect: as the refurbishing rate increases, the expected profit increases noting numerical example two (as in Fig. 4). In this situation, the manufacturer can hold more return products. Also, the manufacturer maintains less inventory of serviceable product 1 (as in Fig. 5). The remanufacturing rate effect is similar to that of the refurbishing rate (as in Figs. 5 and 6). The difference is because by increasing the remanufacturing rate, the manufacturer holds less inventory of the serviceable product 2 .

Return rate effect: as the return rate of products increases, the price of the serviceable products 1 and 2 reduces as the results from numerical example two (as in Fig. 7). The results show that the system profit is at its highest value (as in Fig. 6).

Recovery cost effect: by increasing the refurbishing cost of the return products (Fig. 8), the price of serviceable product 1 increases noting numerical example three (as in Fig. 10). Also, in this situation, less inventory is maintained in the system (as in Fig. 9). If the refurbishing cost can be reduced by improving manufacturing technology, the expected profit increases remarkably and less inventory is maintained. Remanufacturing cost effect is the same as the refurbishing cost (as in Figs. 11-13).

Lost sale cost effect: by increasing the lost sale cost of the serviceable product 1 , more inventory of the serviceable product 1 is maintained noting numerical example three (as in Fig. 15). Also, in this situation, the 
TABLE 4. Results of numerical example 1.

\begin{tabular}{|c|c|c|c|c|c|c|}
\hline $\begin{array}{l}\text { Problem } \\
\text { No. }\end{array}$ & $\left(R, S_{1}, S_{2}\right)$ & Method & $\begin{array}{l}\text { Long-run } \\
\text { expected profit }\end{array}$ & Runtime & $\left(p_{1}, p_{2}\right)$ & $\begin{array}{l}\left(R, S_{1}, S_{2}\right) \\
\text { optimal }\end{array}$ \\
\hline \multirow[t]{4}{*}{$1-1$} & \multirow[t]{3}{*}{$(2,2,5)$} & Numerical search & 280.03 & 16.93 & $(46.82,53.45)$ & $(2,2,4)$ \\
\hline & & $\triangle \mathrm{BC} \quad$ Mean & 280.03 & 0.06 & $(46.82,53.45)$ & $(2,2,4)$ \\
\hline & & SD & 0 & 0 & $(0,0)$ & - \\
\hline & & Error (\% Error) & $0(0 \%)$ & & $(0,0)$ & $(0,0,0)$ \\
\hline \multirow[t]{4}{*}{$1-2$} & \multirow[t]{4}{*}{$(2,5,10)$} & Numerical search & 361.02 & 415.58 & $(41.89,54.81)$ & $(2,5,4)$ \\
\hline & & $\mathrm{ABC} \quad$ Mean & 361.02 & 0.17 & $(41.89,54.81)$ & $(2,5,4)$ \\
\hline & & $\mathrm{ABC} \quad \mathrm{SD}$ & 0 & 0 & $(0,0)$ & - \\
\hline & & Error (\% Error) & $0(0 \%)$ & & $(0,0)$ & $(0,0,0)$ \\
\hline \multirow[t]{4}{*}{$1-3$} & \multirow[t]{4}{*}{$(2,10,5)$} & Numerical search & 377.14 & 527.48 & $(39.30,53.67)$ & $(2,9,5)$ \\
\hline & & \multirow{2}{*}{$\begin{array}{ll}\text { ABC } & \text { Mean } \\
& \text { SD }\end{array}$} & 377.14 & 0.24 & $(39.30,53.67)$ & $(2,9,5)$ \\
\hline & & & 0 & 0 & $(0,0)$ & - \\
\hline & & Error (\% Error) & $0(0 \%)$ & & $(0,0)$ & $(0,0,0)$ \\
\hline \multirow[t]{4}{*}{$1-4$} & \multirow[t]{4}{*}{$(5,5,5)$} & Numerical search & 434.18 & 852.61 & $(38.58,53.26)$ & $(5,5,4)$ \\
\hline & & \multirow{2}{*}{$\begin{array}{ll}\mathrm{ABC} & \text { Mean } \\
& \mathrm{SD}\end{array}$} & 434.18 & 0.25 & $(38.58,53.26)$ & $(5,5,4)$ \\
\hline & & & 0 & 0 & $(0,0)$ & - \\
\hline & & Error (\% Error) & $0(0 \%)$ & & $(0,0)$ & $(0,0,0)$ \\
\hline \multirow[t]{4}{*}{$1-5$} & \multirow[t]{4}{*}{$(5,10,15)$} & \multirow{4}{*}{$\begin{array}{l}\begin{array}{l}\text { Numerical search } \\
\text { MBC }\end{array} \\
\begin{array}{l}\text { SD } \\
\text { SD }\end{array} \\
\text { Error (\% Error) }\end{array}$} & 440.63 & 6392.48 & $(36.98,53.59)$ & $(5,7,4)$ \\
\hline & & & 440.63 & 0.58 & $(36.98,53.59)$ & $(5,7,4)$ \\
\hline & & & 0 & 0.03 & $(0,0)$ & - \\
\hline & & & $0(0 \%)$ & & $(0,0)$ & $(0,0,0)$ \\
\hline \multirow[t]{4}{*}{$1-6$} & \multirow[t]{4}{*}{$(10,10,10)$} & Simulation method & 461.83 & 168.35 & $(36.28,52.81)$ & $(10,6,4)$ \\
\hline & & \multirow{3}{*}{$\begin{array}{cl}\text { ABC } & \begin{array}{l}\text { Mean } \\
\text { SD }\end{array} \\
\text { Error (\% Error })\end{array}$} & 463.10 & 1.34 & $(36.33,52.70)$ & $(10,6,4)$ \\
\hline & & & 0 & 0.11 & $(0,0)$ & - \\
\hline & & & $1.17(0.25 \%)$ & & $(0.05,0.11)$ & $(0,0,0)$ \\
\hline \multirow[t]{4}{*}{$1-7$} & \multirow[t]{4}{*}{$(15,10,20)$} & Simulation method & 468.23 & 218.12 & $(35.56,52.24)$ & $(15,6,4)$ \\
\hline & & ABC Mean & 467.96 & 3.78 & $(35.49,52.22)$ & $(15,6,4)$ \\
\hline & & SD & 0 & 0.52 & $(0,0)$ & - \\
\hline & & Error (\% Error) & $0.27(0.02 \%)$ & $(0.07,0.02)$ & $(0,0,0)$ & \\
\hline $1-8$ & $(20,15,10)$ & Simulation method & 469.12 & 241.98 & $(35.22,52.19)$ & $(15,6,4)$ \\
\hline & & ABC Mean & 468.03 & 6.46 & $(35.34,52.14)$ & $(16,6,4)$ \\
\hline & & SD & 0 & 0.45 & $(0,0)$ & - \\
\hline & & Error (\% Error) & $1.09(0.23 \%)$ & & $(0.12,0.05)$ & $(0,0,0)$ \\
\hline $1-9$ & $(20,20,20)$ & Simulation method & 464.15 & 298.59 & $(35.12,51.36)$ & $(16,6,4)$ \\
\hline & & BC Mean & 468.03 & 15.19 & $(35.34,52.14)$ & $(16,6,4)$ \\
\hline & & ADC $\quad \mathrm{SD}$ & 0 & 0.57 & $(0,0)$ & - \\
\hline & & Error (\% Error) & $3.88(0.8 \%)$ & & $(0.22,0.78)$ & $(0,0,0)$ \\
\hline
\end{tabular}

price of the serviceable product 1 increases due to the system profitability (as in Fig 16). If using appropriate strategies make customers be loyal, less inventory is maintained and the expected profit increases remarkably (as in Fig. 14). The lost sale cost effect of the serviceable product 2 has a result similar to that of serviceable product 1 (as in Figs. 17-19).

Disposal cost effect: by increasing the disposal cost of return products (Fig. 20), the disposing of return products decreases and more inventory is maintained in the system noting numerical example three (as in Fig. 21). In this situation, due to the high inventory of the system, the price of the serviceable products decreases in order to be profitable (as in Fig. 22).

Price elasticity of demand: if the demand rate is less sensitive toward the price (Fig. 23), the price of the serviceable product 1 can be considered equal to a high value to be profitable noting numerical example three 
TABLE 5. Results of numerical example 2.

\begin{tabular}{|c|c|c|c|c|c|c|}
\hline $\begin{array}{l}\text { Problem } \\
\text { No. }\end{array}$ & $\left(R, S_{1}, S_{2}\right)$ & Method & $\begin{array}{l}\text { Long-run } \\
\text { expected profit }\end{array}$ & Runtime & $\left(p_{1}, p_{2}\right)$ & $\begin{array}{l}\left(R, S_{1}, S_{2}\right) \\
\text { optimal }\end{array}$ \\
\hline \multirow[t]{4}{*}{$2-1$} & \multirow{4}{*}{$(2,2,5)$} & Numerical search & 250.49 & 16.93 & $(41.82,50.37)$ & $(2,2,5)$ \\
\hline & & \multirow{3}{*}{$\begin{array}{ll}\text { ABC } & \begin{array}{l}\text { Mean } \\
\text { SD }\end{array} \\
& \text { Frror }(\% \text { Error })\end{array}$} & 250.49 & 0.15 & $(41.82,50.37)$ & $(2,2,5)$ \\
\hline & & & 0 & 0 & $(0,0)$ & - \\
\hline & & & $0(0 \%)$ & & $(0,0)$ & $(0,0,0)$ \\
\hline \multirow[t]{4}{*}{$2-2$} & \multirow[t]{4}{*}{$(2,5,10)$} & Numerical search & 261.02 & 415.58 & $(38.82,51.89)$ & $(2,5,5)$ \\
\hline & & \multirow{2}{*}{$\begin{array}{ll}\text { ABC } & \text { Mean } \\
& \text { SD }\end{array}$} & 261.02 & 0.17 & $(38.82,51.89)$ & $(2,5,5)$ \\
\hline & & & 0 & 0.01 & $(0,0)$ & - \\
\hline & & Error (\% Error) & $0(0 \%)$ & & $(0,0)$ & $(0,0,0)$ \\
\hline \multirow[t]{4}{*}{$2-3$} & \multirow{4}{*}{$(2,10,5)$} & Numerical search & 278.19 & 527.04 & $(36.30,51.62)$ & $(2,9,5)$ \\
\hline & & \multirow{2}{*}{$\begin{array}{ll}\mathrm{ABC} & \text { Mean } \\
& \mathrm{SD}\end{array}$} & 278.18 & 0.24 & $(36.30,51.62)$ & $(2,9,5)$ \\
\hline & & & 0 & 0.01 & $(0,0)$ & - \\
\hline & & Error (\% Error) & $0.01(0 \%)$ & & $(0,0)$ & $(0,0,0)$ \\
\hline \multirow[t]{4}{*}{$2-4$} & \multirow{4}{*}{$(5,5,5)$} & Numerical search & 302.18 & 852.61 & $(35.88,51.26)$ & $(5,5,4)$ \\
\hline & & \multirow{3}{*}{$\begin{array}{cl}\mathrm{ABC} & \begin{array}{l}\text { Mean } \\
\mathrm{SD}\end{array} \\
\text { Frror }(\% \text { Frror })\end{array}$} & 302.18 & 0.25 & $(35.88,51.26)$ & $(5,5,4)$ \\
\hline & & & 0 & 0.1 & $(0,0)$ & - \\
\hline & & & $0(0 \%)$ & & $(0,0)$ & $(0,0,0)$ \\
\hline \multirow[t]{4}{*}{$2-5$} & \multirow[t]{4}{*}{$(10,10,10)$} & Simulation method & 361.82 & 168.35 & $(35.28,51.80)$ & $(10,6,6)$ \\
\hline & & \multirow{3}{*}{$\begin{array}{ll}\text { ABC } & \text { Mean } \\
& \text { SD } \\
\end{array}$} & 363.10 & 1.38 & $(35.31,52.69)$ & $(10,6,6)$ \\
\hline & & & 0 & 0.11 & $(0,0)$ & - \\
\hline & & & $1.28(0.35 \%)$ & & $(0.03,0.11)$ & $(0,0,0)$ \\
\hline \multirow[t]{4}{*}{$2-6$} & \multirow[t]{4}{*}{$(10,10,15)$} & Simulation method & 364.23 & 169.05 & $(35.34,52.12)$ & $(10,6,8)$ \\
\hline & & \multirow{3}{*}{$\begin{array}{c}\text { ABC } \begin{array}{l}\text { Mean } \\
\text { SD }\end{array} \\
\text { Error }(\% \text { Error })\end{array}$} & 367.93 & 1.49 & $(35.33,52.43)$ & $(10,6,8)$ \\
\hline & & & 0 & 0.23 & $(0,0)$ & - \\
\hline & & & $3.7(1 \%)$ & & $(0.05,0.31)$ & $(0,0,0)$ \\
\hline \multirow[t]{4}{*}{$2-7$} & \multirow[t]{4}{*}{$(10,15,10)$} & Simulation method & 367.83 & 169.42 & $(38.49,50.81)$ & $(10,10,5)$ \\
\hline & & Mean & 366.12 & 3.69 & $(37.33,50.97)$ & $(10,10,5)$ \\
\hline & & $\mathrm{SD}$ & 0 & 0.56 & $(0,0)$ & - \\
\hline & & Error (\% Error) & $1.71(0.47 \%)$ & & $(1.06,0.16)$ & $(0,0,0)$ \\
\hline $2-8$ & $(15,15,15)$ & Simulation method & 421.73 & 175.34 & $(37.33,51.79)$ & $(10,12,10)$ \\
\hline & & Bean & 419.85 & 6.11 & $(36.48,52.07)$ & $(10,12,9)$ \\
\hline & & $\mathrm{SD}$ & 0 & 0.58 & $(0,0)$ & - \\
\hline & & Error (\% Error) & $1.88(0.44 \%)$ & & $(0.85,0.28)$ & $(0,0,1)$ \\
\hline $2-9$ & $(20,20,20)$ & Simulation method & 460.86 & 196.86 & $(34.98,50.90)$ & $(10,12,12)$ \\
\hline & & Mean & 463.10 & 8.74 & $(34.33,52.70)$ & $(10,12,12)$ \\
\hline & & $\mathrm{SD}$ & 0 & 0.61 & $(0,0)$ & - \\
\hline & & Error (\% Error) & $2.24(0.48 \%)$ & & $(0.65,0.20)$ & $(0,0,0)$ \\
\hline
\end{tabular}

(as in Fig. 25). In this situation, due to the customer's high demand, more inventory should be maintained in the system (as in Fig. 24). If the demand rate is more sensitive toward the price, the price of the serviceable product 1is considered to be low and in this situation, due to the low demand rate, less inventory is maintained in the system. The sensitivity analysis of $\beta_{2}$ is similar to $\beta_{1}$ (as in Figs. 26-28).

The results of sensitivity analysis led to the following managerial insights:

- If the manufacturer increases remanufacturing and refurbishing rates using appropriate strategies such as improving production technology or increasing the number of manpower, the expected profit function will also increase.

- The manufacturer should consider product return rates as a decision variable and obtain the optimal return rate. For this purpose, it is recommended to consider the return rate as a function of the purchase price of 
TABLE 6. Results of numerical example 3 .

\begin{tabular}{|c|c|c|c|c|c|c|}
\hline $\begin{array}{l}\text { Problem } \\
\text { No. }\end{array}$ & $\left(R, S_{1}, S_{2}\right)$ & Method & $\begin{array}{l}\text { Long-run } \\
\text { expected profit }\end{array}$ & Runtime & $\left(p_{1}, p_{2}\right)$ & $\begin{array}{l}\left(R, S_{1}, S_{2}\right) \\
\text { optimal }\end{array}$ \\
\hline \multirow[t]{4}{*}{$3-1$} & \multirow{4}{*}{$(2,2,5)$} & Numerical search & 358.93 & 17.93 & $(36.72,53.14)$ & $(2,2,4)$ \\
\hline & & \multirow{3}{*}{$\begin{array}{cl}\text { ABC } & \begin{array}{l}\text { Mean } \\
\text { SD }\end{array} \\
& \text { Error }(\% \text { Error })\end{array}$} & 358.93 & 0.08 & $(36.72,53.14)$ & $(2,2,4)$ \\
\hline & & & 0 & 0 & $(0,0)$ & - \\
\hline & & & $0(0 \%)$ & & $(0,0)$ & $(0,0,0)$ \\
\hline \multirow[t]{4}{*}{$3-2$} & \multirow[t]{4}{*}{$(2,5,10)$} & Numerical search & 371.02 & 415.58 & $(36.49,52.81)$ & $(2,5,5)$ \\
\hline & & \multirow{2}{*}{$\begin{array}{ll}\text { ABC } & \text { Mean } \\
& \text { SD }\end{array}$} & 371.02 & 0.19 & $(36.49,52.81)$ & $(2,5,5)$ \\
\hline & & & 0 & 0.01 & $(0,0)$ & - \\
\hline & & Error (\% Error) & $0(0 \%)$ & & $(0,0)$ & $(0,0,0)$ \\
\hline \multirow[t]{4}{*}{$3-3$} & $(2,10,5)$ & Numerical search & 397.75 & 527.48 & $(35.67,52.26)$ & $(2,8,5)$ \\
\hline & & \multirow{2}{*}{$\begin{array}{ll}\mathrm{ABC} & \text { Mea } \\
\mathrm{SD}\end{array}$} & 397.73 & 0.24 & $(35.67,52.25)$ & $(2,8,5)$ \\
\hline & & & 0 & 0.02 & $(0,0)$ & - \\
\hline & & Error (\% Error) & $0.02(0.00 \%)$ & & $(0,0)$ & $(0,0,0)$ \\
\hline \multirow[t]{4}{*}{$3-4$} & $(5,5,5)$ & Numerical search & 434.86 & 852.02 & $(35.58,51.96)$ & $(5,5,4)$ \\
\hline & & \multirow{2}{*}{$\begin{array}{ll}\text { ABC } & \text { Mean } \\
& \text { SD }\end{array}$} & 434.85 & 0.36 & $(35.58,51.96)$ & $(5,5,4)$ \\
\hline & & & 0 & 0.2 & $(0,0)$ & - \\
\hline & & Error (\% Error) & $0.01(0 \%)$ & & $(0,0)$ & $(0,0,0)$ \\
\hline \multirow[t]{4}{*}{$3-5$} & $(15,15,15)$ & Simulation method & 489.61 & 175.35 & $(34.18,49.81)$ & $(10,7,6)$ \\
\hline & & \multirow{2}{*}{$\begin{array}{ll}\text { ABC } & \text { Mean } \\
& \text { SD }\end{array}$} & 493.00 & 6.34 & $(33.93,49.70)$ & $(10,7,6)$ \\
\hline & & & 0 & 0.68 & $(0,0)$ & - \\
\hline & & Error (\% Error) & $3.39(0.69 \%)$ & & $(0.2,0.11)$ & $(0,0,0)$ \\
\hline \multirow[t]{4}{*}{$3-6$} & $(15,15,20)$ & Simulation method & 490.22 & 198.86 & $(34.09,49.78)$ & $(10,10,9)$ \\
\hline & & \multirow{2}{*}{ ABC $\quad \begin{array}{l}\text { Mean } \\
\text { SD }\end{array}$} & 488.69 & 7.24 & $(34.33,50.40)$ & $(10,10,8)$ \\
\hline & & & 0 & 0.71 & $(0,0)$ & - \\
\hline & & Error (\% Error) & $1.53(0.003 \%)$ & & $(0.24,0.62)$ & $(0,0,1)$ \\
\hline \multirow[t]{4}{*}{$3-7$} & $(15,20,15)$ & Simulation method & 491.83 & 199.35 & $(34.08,50.18)$ & $(10,11,5)$ \\
\hline & & Mean & 493.10 & 7.34 & $(34.31,49.98)$ & $(10,12,5)$ \\
\hline & & $\mathrm{ABC}$ & 0 & 0.68 & $(0,0)$ & - \\
\hline & & Error (\% Error) & $1.17(0.31 \%)$ & & $(0.23,0.2)$ & $(0,1,0)$ \\
\hline $3-8$ & $(20,15,20)$ & Simulation method & 496.38 & 200.05 & $(34.33,49.81)$ & $(13,8,10)$ \\
\hline & & Bean & 492.73 & 8.69 & $(34.62,50.07)$ & $(13,8,11)$ \\
\hline & & $\mathrm{SD}$ & 0 & 0.71 & $(0,0)$ & - \\
\hline & & Error (\% Error) & $3.65(0.74 \%)$ & & $(0.29,0.26)$ & $(0,0,1)$ \\
\hline $3-9$ & $(20,20,20)$ & Simulation method & 496.12 & 217.95 & $(32.75,48.93)$ & $(14,13,10)$ \\
\hline & & Mean & 499.96 & 10.03 & $(32.69,48.26)$ & $(13,12,10)$ \\
\hline & & IBC $\quad$ SD & 0 & 0.78 & $(0,0)$ & - \\
\hline & & Error (\% Error) & $3.84(0.77 \%)$ & & $(0.06,0.67)$ & $(1,1,0)$ \\
\hline
\end{tabular}

return products. The manufacturer should manage the return rate of the products by adjusting the purchase price of return products.

- When the recovery cost is high in the system or disposal cost is low, the manufacturer should hold less inventory in the system and consider a higher price for the serviceable products.

- When the lost sale cost is high, the manufacturer should hold more inventory in the system and consider the serviceable products price.

- When demand is less sensitive toward products price, the manufacturer should consider the price of the serviceable products higher and hold more inventory in the system. 


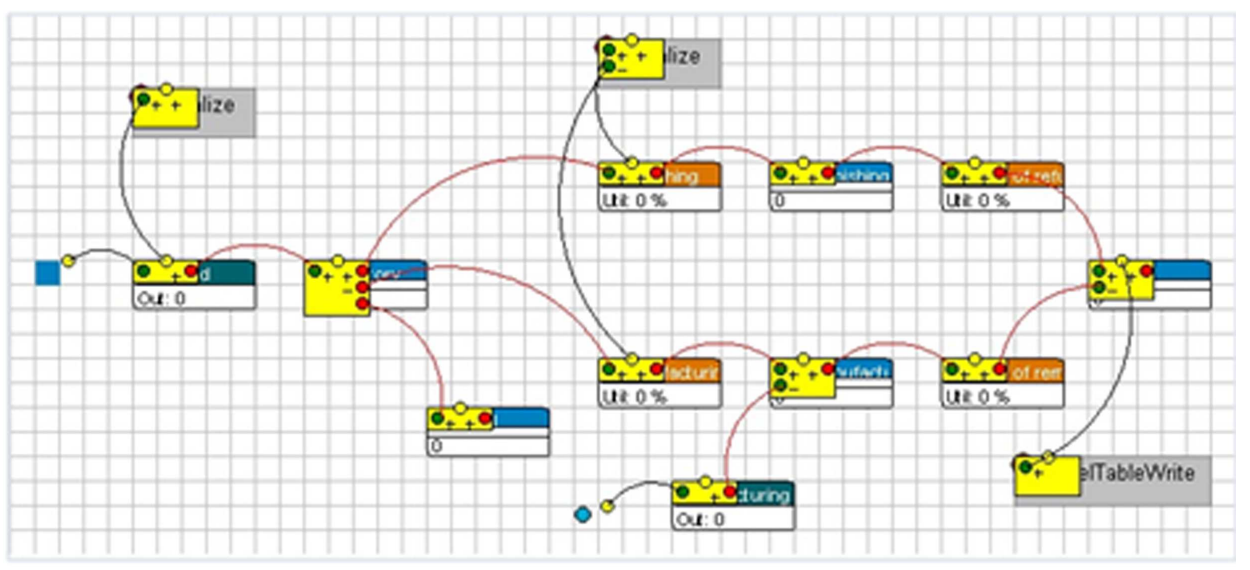

FiguRE 3. ED view of model.

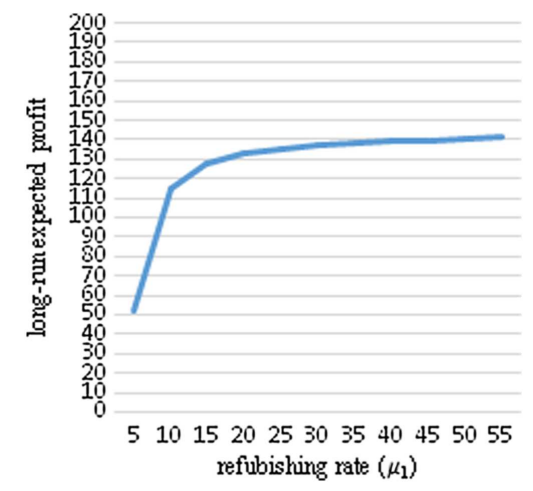

FiguRE 4. Effect of the refurbishing rate on the long-run expected profit.

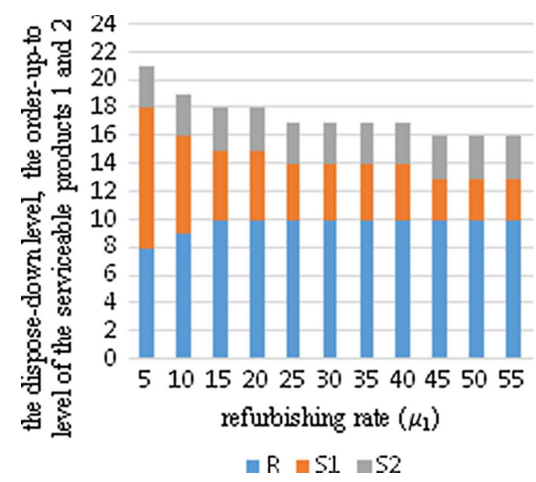

FIGURE 5. Effect of the refurbishing rate on the dispose-down level, the order-up-to level of the serviceable products 1 and 2 . 


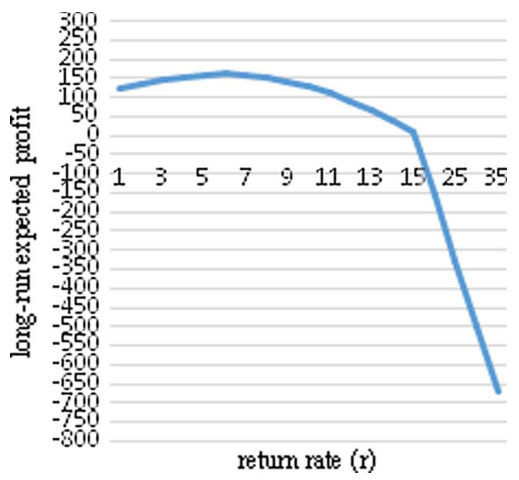

FiguRE 6. Effect of the return rate on the long-run expected profit.

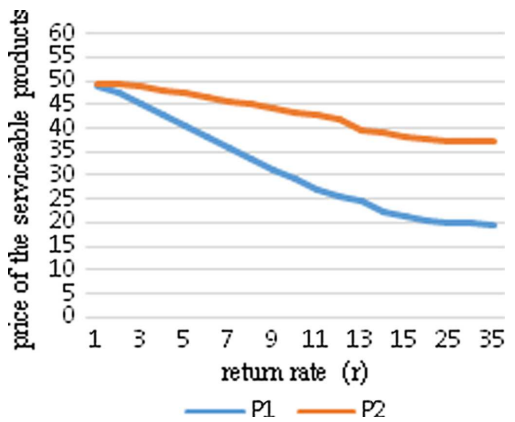

FiguRE 7. Effect of the return rate on the price of the serviceable product 1 and 2 .

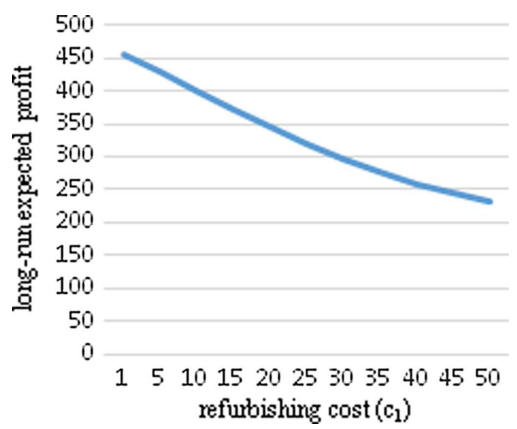

FIGURE 8. Effect of the refurbishing rate on the long-run expected profit.

\section{CONCLUSION AND FURTHER RESEARCH IDEAS}

In this paper, a hybrid production system including a refurbishment process, a manufacturing process, and a remanufacturing process is considered. The demand rate is a linear function of the price and the demand. The demand and return have Poisson distributions. The system inventory position is modeled as a threedimensional Markov chain. Using the steady state probabilities and the sale price of serviceable products, the long-run expected profit function is obtained as a function of the dispose-down-to level of returned products and the order-up-to level and the sale price of serviceable products. The two serviceable products are replenished 


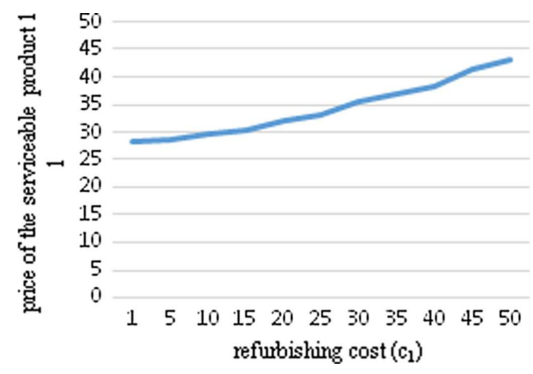

FiguRE 9. Effect of the refurbishing rate on the dispose-down level, the order-up-to level of the serviceable products 1 .

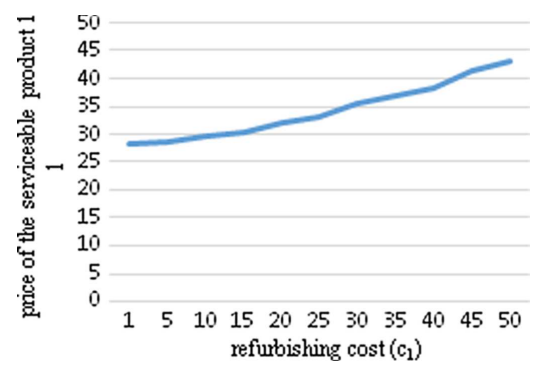

FiguRE 10. Effect of refurbishing cost on the price of the serviceable product 1 .

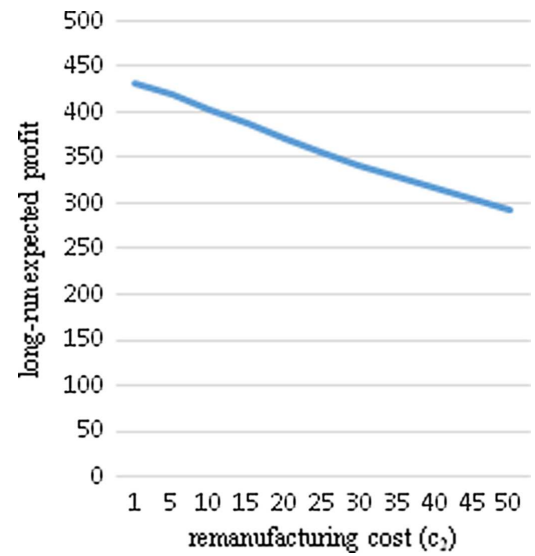

FigURE 11. Effect of the remanufacturing cost on the long-run expected profit.

according to the base stock policy. The complete search method and the ABC algorithm are used to obtain the optimal solution for small- and large-scale examples. Furthermore, the impact of the parameters on the optimal solution and the long-run expected profit is investigated. The results show that the number of returned products increases by increasing the purchase price of returned products. Less inventory should be maintained in the system with a high price of serviceable products whether the refurbishing cost of the return products is high or the disposal cost is low. Higher inventory should be maintained by increasing the lost sale cost. In addition, by decreasing the price elasticity of the demand, the customer demand increases, and correspondingly, higher inventory should be maintained in the system. 


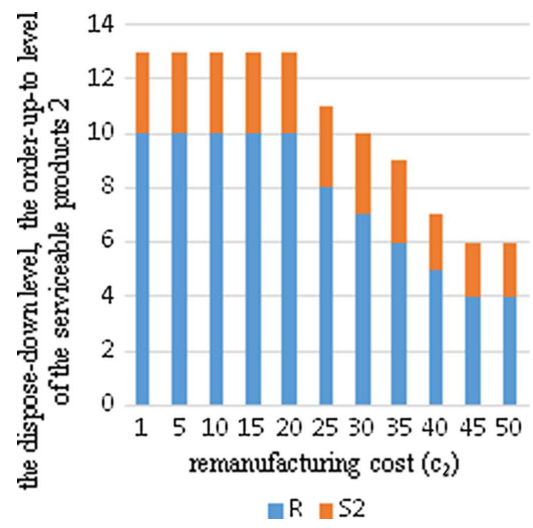

FigURE 12. Effect of the remanufacturing cost on the dispose-down level, the order-up-to level of the serviceable products 2 .

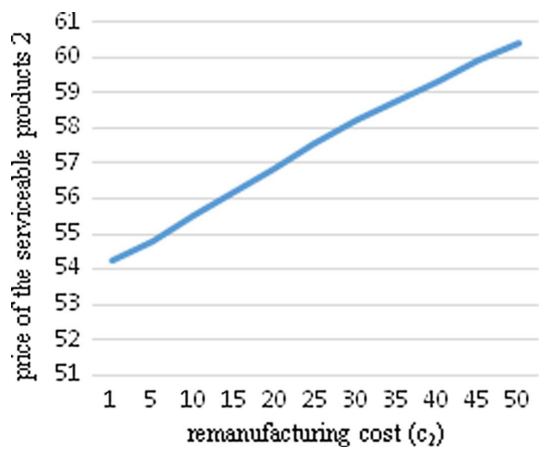

Figure 13. Effect of the remanufacturing cost on the price of the serviceable products 2.

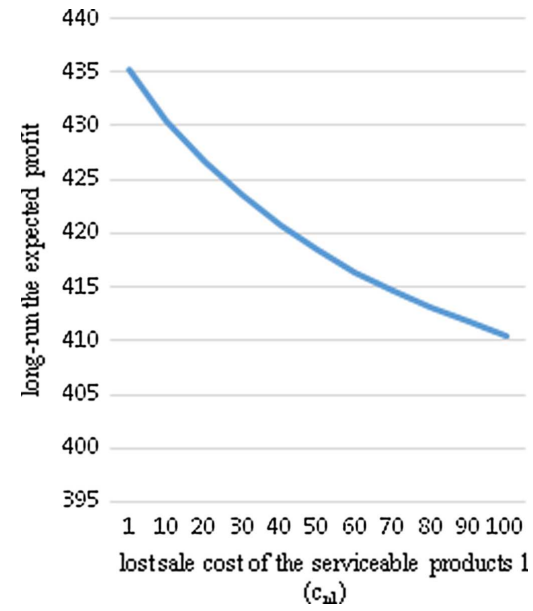

Figure 14. Effect of the lost sale cost of the serviceable products 1 on the long-run expected profit. 


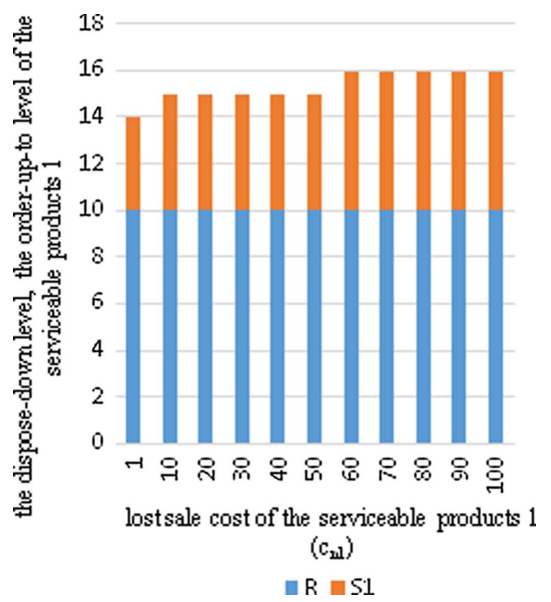

FiguRE 15. Effect of the lost sale cost of the serviceable products 1 on the dispose-down level, the order-up-to level of the serviceable products 1.

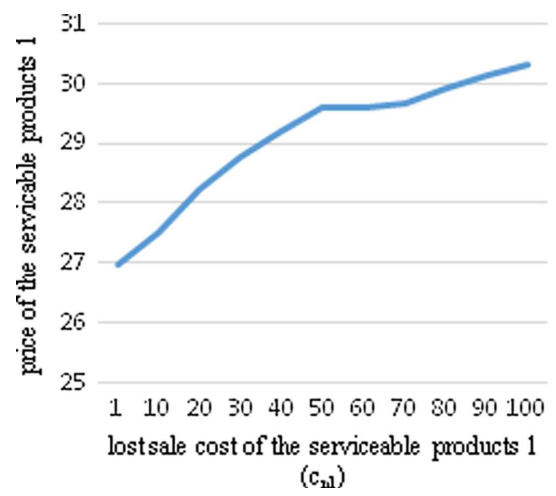

FiguRE 16. Effect of the lost sale cost of the serviceable products 1 on its price.

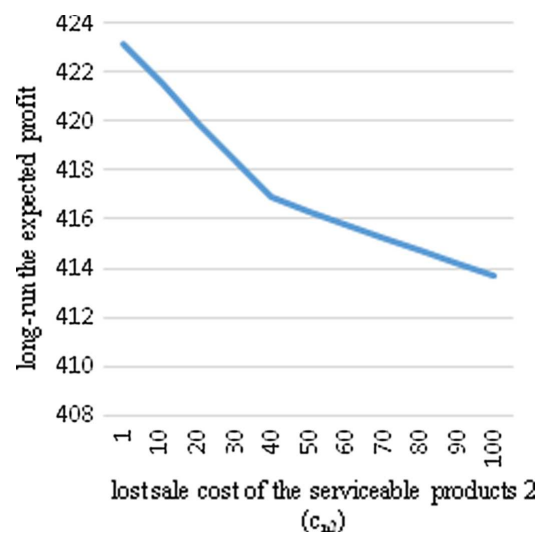

Figure 17. Effect of the lost sale cost of the serviceable products 2 on the long-run expected profit. 


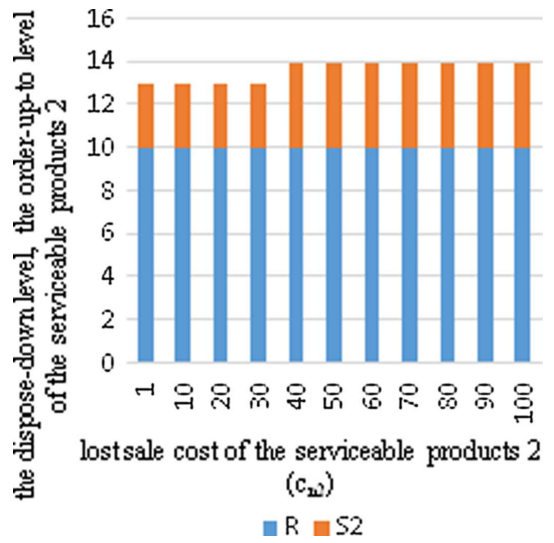

FiguRE 18. Effect of the lost sale cost of the serviceable products 2 on the dispose-down level, the order-up-to level of the serviceable products 2 .

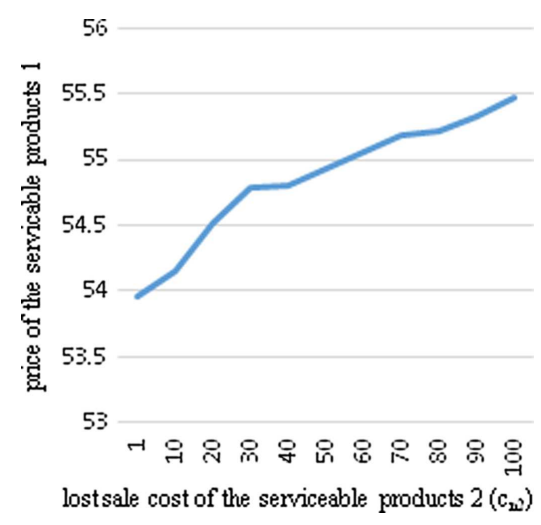

Figure 19. Effect of the lost sale cost of the serviceable products 2 on its price.

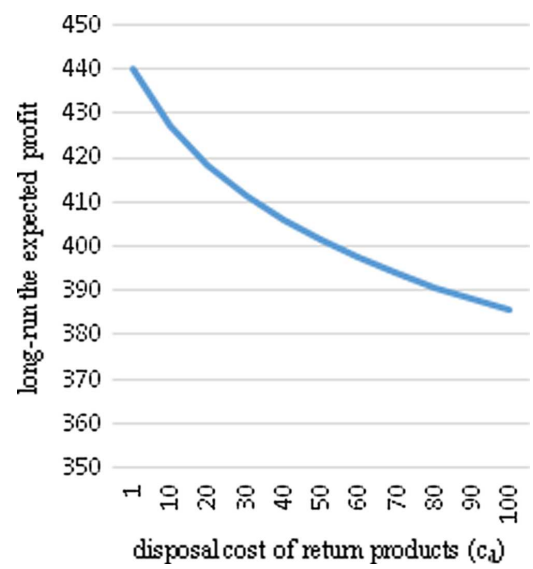

Figure 20. Effect of the disposal cost of return products on the long-run expected profit. 


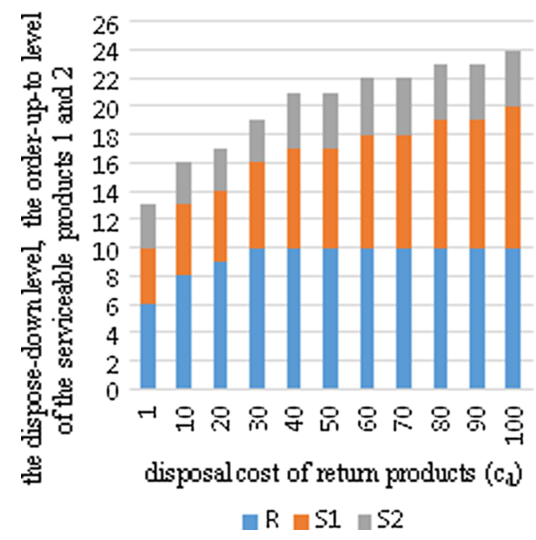

FigURE 21. Effect of the disposal cost of return products on the dispose-down level, the orderup-to level of the serviceable products 1 and 2 .

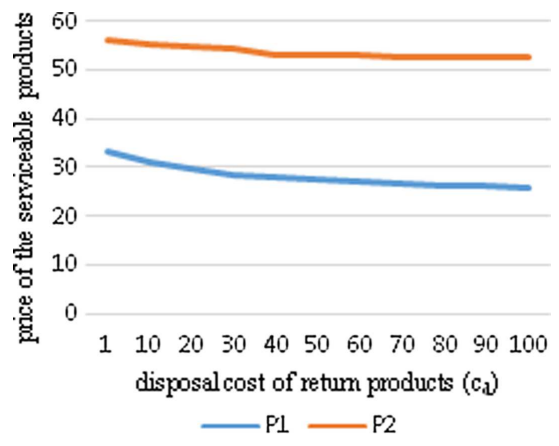

FIGURE 22. Effect of the disposal cost of return products on the price of the serviceable products 1 and 2 .

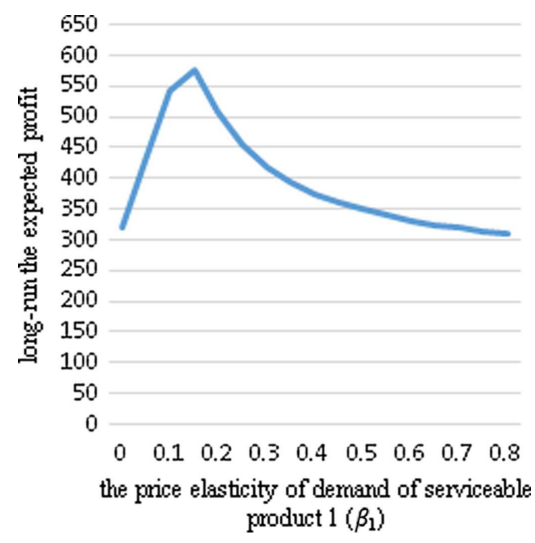

Figure 23. Effect of the price elasticity of demand of serviceable product 1 on the long-run expected profit. 


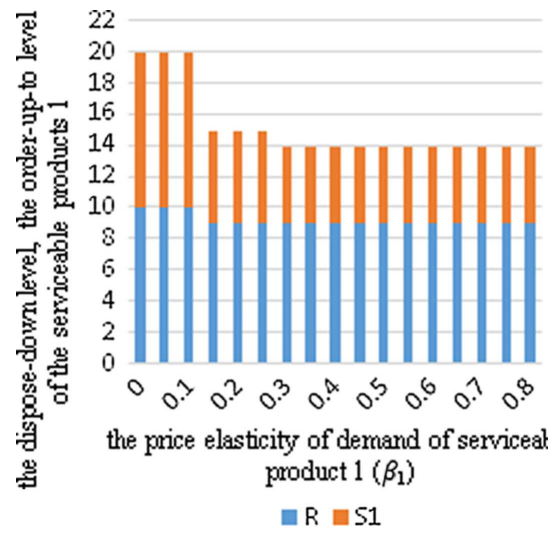

FIGURE 24. Effect of the price elasticity of demand of serviceable product 1 on the dispose-down level, the order-up-to level of the serviceable products 1 .

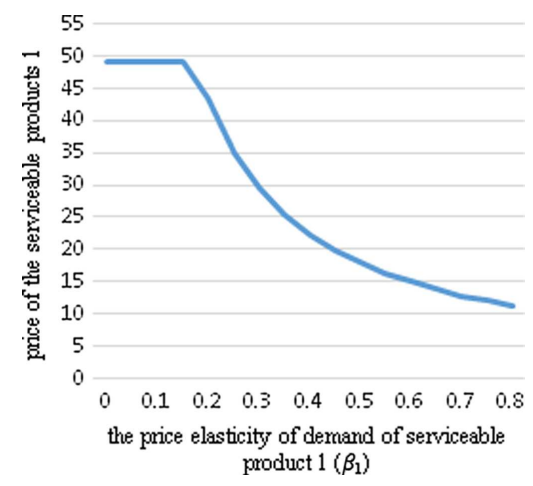

FiguRE 25. Effect of the price elasticity of demand of serviceable product 1 on its price.

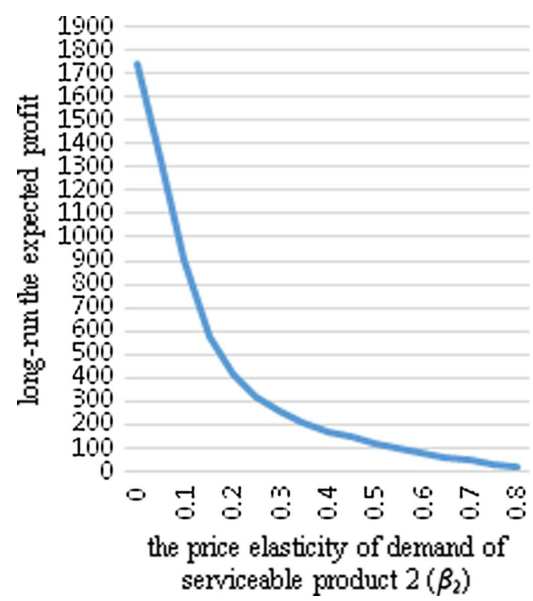

FIGURE 26. Effect of price elasticity of demand of serviceable product 2 on the long-run expected. 


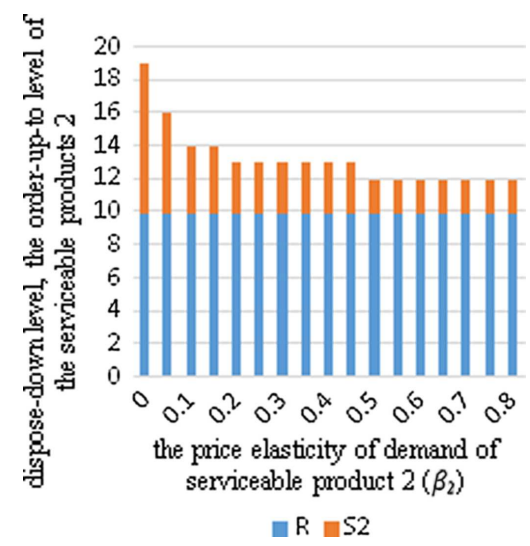

FIGURE 27. Effect of the price elasticity of demand of serviceable product 2 on the dispose-down level, the order-up-to level of the serviceable products 2 .

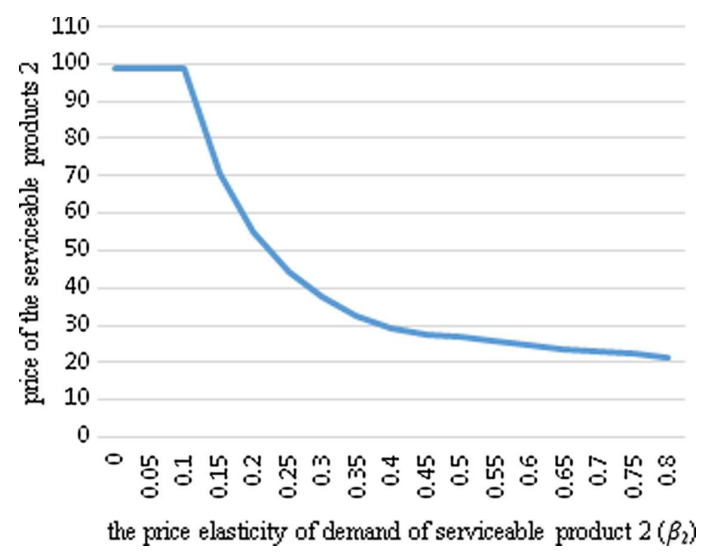

FIGURE 28. Effect of price elasticity of product 2 on its price.

There are several ways to extend this paper. We have assumed that the quality level of returned products are the same. Relaxing this assumptions makes the problem more realistic and more complex. Other inventory policies such as continuous review or adaptive pull could be considered for further research. A supply chain structure with higher echelons and more recovery options for the returned products can be also considered for future research.

\section{Appendix A.}

Markov chain rate matrix $(Q)$, based on the listed states in Section 2.4 is as follows:

$$
Q=\left(\begin{array}{cccccccc}
D_{0} & B & 0 & 0 & \cdots & 0 & 0 & 0 \\
C & D_{1} & B & 0 & \cdots & 0 & 0 & 0 \\
0 & C & D_{1} & B & \cdots & 0 & 0 & 0 \\
0 & 0 & C & D_{1} & \cdots & B & 0 & 0 \\
\vdots & \vdots & \vdots & \vdots & \ddots & \vdots & \vdots & \vdots \\
0 & 0 & 0 & 0 & \cdots & C & D_{1} & B \\
0 & 0 & 0 & 0 & \cdots & 0 & C & D_{R}
\end{array}\right)
$$


where $B, C, D_{j}(j=0,1, R)$ are $\left(S_{1}+1\right)\left(S_{2}+1\right)\left(S_{1}+1\right)\left(S_{2}+1\right)$ matrices and are given by:

$$
\begin{aligned}
B & =\left(\begin{array}{cccccc}
B_{1} & 0 & 0 & \cdots & 0 & 0 \\
0 & B_{1} & 0 & \cdots & 0 & 0 \\
0 & 0 & B_{1} & \cdots & 0 & 0 \\
0 & 0 & 0 & \cdots & 0 & 0 \\
\vdots & \vdots & \vdots & \ddots & \vdots & \vdots \\
0 & 0 & 0 & \cdots & B_{1} & 0 \\
0 & 0 & 0 & \cdots & 0 & B_{1}
\end{array}\right) \\
C & =\left(\begin{array}{cccccc}
C_{1} & C_{2} & 0 & \cdots & 0 & 0 \\
0 & C_{1} & C_{2} & \cdots & 0 & 0 \\
0 & 0 & C_{1} & \cdots & 0 & 0 \\
0 & 0 & 0 & \cdots & 0 & 0 \\
\vdots & \vdots & \vdots & \ddots & \vdots & \vdots \\
0 & 0 & 0 & \cdots & C_{1} & C_{2} \\
0 & 0 & 0 & \cdots & 0 & C_{1}
\end{array}\right) \\
D_{j} & =\left(\begin{array}{ccccccc}
D_{1}^{j} & 0 & 0 & 0 & \cdots & 0 & 0 \\
D_{2} & D_{2}^{j} & 0 & 0 & \cdots & 0 & 0 \\
0 & D_{2} & D_{2}^{j} & 0 & \cdots & 0 & 0 \\
0 & 0 & D_{2} & D_{2}^{j} & \cdots & 0 & 0 \\
\vdots & \vdots & \vdots & \ddots & \vdots & \vdots & \\
0 & 0 & 0 & 0 & \cdots & 0 & 0 \\
0 & 0 & 0 & 0 & \cdots & D_{2} & D_{2}^{j}
\end{array}\right)(j=0,1, R) .
\end{aligned}
$$

Also, $C_{1}, C_{2}, B_{1}, D_{2}, D_{1}^{j}, D_{2}^{j}, D_{S_{1}}^{j}(j=0,1, R)$ are $\left(S_{2}+1\right)\left(S_{2}+1\right)$ matrices and are given by:

$$
\begin{aligned}
& B_{1}=\left(\begin{array}{cccccc}
r & 0 & 0 & \cdots & 0 & 0 \\
0 & r & 0 & \cdots & 0 & 0 \\
0 & 0 & r & \cdots & 0 & 0 \\
0 & 0 & 0 & \cdots & 0 & 0 \\
\vdots & \vdots & \vdots & \ddots & \vdots & \vdots \\
0 & 0 & 0 & \cdots & r & 0 \\
0 & 0 & 0 & \cdots & 0 & r
\end{array}\right) \\
& D_{2}=\left(\begin{array}{cccccc}
\lambda_{1} & 0 & 0 & \ldots & 0 & 0 \\
0 & \lambda_{1} & 0 & \ldots & 0 & 0 \\
0 & 0 & \lambda_{1} & \ldots & 0 & 0 \\
0 & 0 & 0 & \cdots & 0 & 0 \\
\vdots & \vdots & \vdots & \ddots & \vdots & \vdots \\
0 & 0 & 0 & \cdots & \lambda_{1} & 0 \\
0 & 0 & 0 & \cdots & 0 & \lambda_{1}
\end{array}\right) \\
& C_{1}=\left(\begin{array}{cccccc}
\mu_{2} & 0 & 0 & \cdots & 0 & 0 \\
0 & \mu_{2} & 0 & \cdots & 0 & 0 \\
0 & 0 & \mu_{2} & \cdots & 0 & 0 \\
0 & 0 & 0 & \cdots & 0 & 0 \\
\vdots & \vdots & \vdots & \ddots & \vdots & \vdots \\
0 & 0 & 0 & \cdots & \mu_{2} & 0 \\
0 & 0 & 0 & \cdots & 0 & \mu_{2}
\end{array}\right) \quad C_{2}=\left(\begin{array}{cccccc}
\mu_{1} & 0 & 0 & \cdots & 0 & 0 \\
0 & \mu_{1} & 0 & \cdots & 0 & 0 \\
0 & 0 & \mu_{1} & \cdots & 0 & 0 \\
0 & 0 & 0 & \cdots & 0 & 0 \\
\vdots & \vdots & \vdots & \ddots & \vdots & \vdots \\
0 & 0 & 0 & \cdots & \mu_{1} & 0 \\
0 & 0 & 0 & \cdots & 0 & \mu_{1}
\end{array}\right)
\end{aligned}
$$

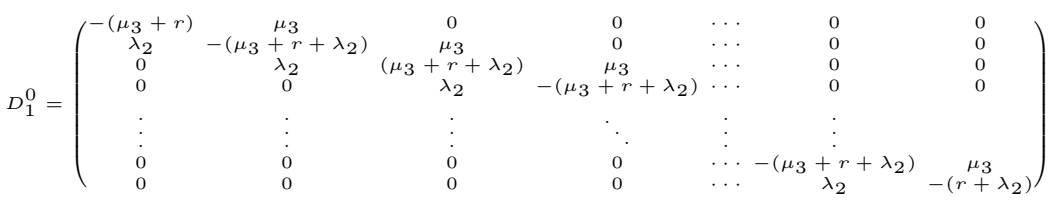

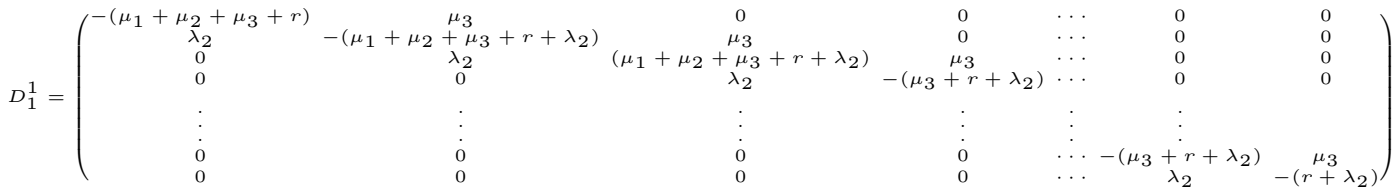




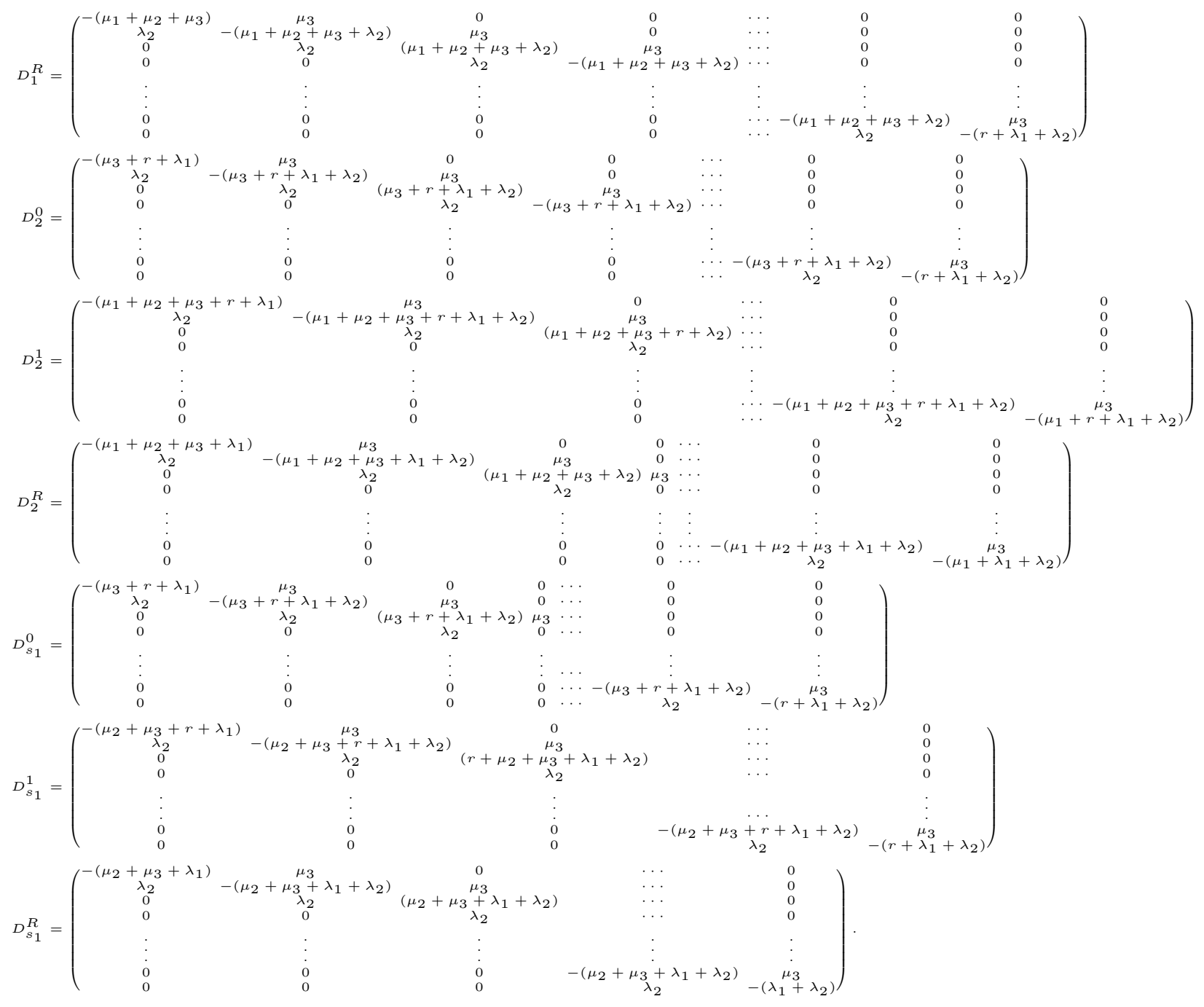

\section{REFERENCES}

[1] S.S. Ahiska and R.E. King, Inventory optimization in a one product recoverable manufacturing system. Int. J. Prod. Econ. 124 (2010) 11-19.

[2] S.S. Ahiska and R.E. King, Life cycle inventory policy characterizations for a single-product recoverable system. Int. J. Prod. Econ. 124 (2010) 51-61.

[3] B. Babayigit and R. Ozdemir, A modified artificial bee colony algorithm for numerical function optimization. In: 2012 IEEE symposium on computers and communications (ISCC). IEEE (2012) 000245-000249.

[4] Z.P. Bayındır, N. Erkip and R. Güllü, Assessing the benefits of remanufacturing option under one-way substitution. J. Oper. Res. Soc. 56 (2005) 286-296.

[5] M.S. Bazaraa, H.D. Sherali and C.M. Shetty, Nonlinear Programming: Theory and Algorithms. John Wiley \& Sons (2013).

[6] E. Benedito and A. Corominas, Optimal manufacturing policy in a reverse logistic system with dependent stochastic returns and limited capacities. Int. J. Prod. Res. 51 (2013) 189-201.

[7] S. Burer and A.N. Letchford, Non-convex mixed-integer nonlinear programming: a survey. Surv. Oper. Res. Manage. Sci. 17 (2012) 97-106.

[8] G.A. DeCroix, Optimal policy for a multiechelon inventory system with remanufacturing. Oper. Res. 54 (2006) $532-543$.

[9] R. Dekker, M. Fleischmann, K. Inderfurth and L.N. van Wassenhove, Reverse Logistics: Quantitative Models for Closed-Loop Supply Chains. Springer Science \& Business Media (2013).

[10] S.D. Flapper, J.-P. Gayon and L.L. Lim, On the optimal control of manufacturing and remanufacturing activities with a single shared server. Eur. J. Oper. Res. 234 (2014) 86-98. 
[11] C. Gao, Y. Wang, L. Xu and Y. Liao, Dynamic pricing and production control of an inventory system with remanufacturing. Math. Prob. Eng. 2015 (2015) 789306.

[12] B.C. Giri, C. Mondal and T. Maiti, Optimal product quality and pricing strategy for a twoperiod closed-loop supply chain with retailer variable markup. RAIRO:OR 53 (2019) 609-626.

[13] D.P. Heyman, Optimal disposal policies for a single-item inventory system with returns. Naval Res. Logistics Q. 24 (1977) 385-405.

[14] K. Inderfurth, Simple optimal replenishment and disposal policies for a product recovery system with leadtimes. Oper. Res. Spectr. 19 (1997) 111-122.

[15] K. Inderfurth, Optimal policies in hybrid manufacturing/remanufacturing systems with product substitution. Int. J. Prod. Econ. 90 (2004) 325-343.

[16] K. Inderfurth and E. van der Laan, Leadtime effects and policy improvement for stochastic inventory control with remanufacturing. Int. J. Prod. Econ. 71 (2001) 381-390.

[17] G.P. Kiesmüller, A new approach for controlling a hybrid stochastic manufacturing/remanufacturing system with inventories and different leadtimes. Eur. J. Oper. Res. 147 (2003) 62-71.

[18] A. Maji, A.K. Bhunia and S.K. Mondal, Exploring a productioninventory model with optimal reliability of the production in a parallel-series system. J. Ind. Prod. Eng. 37 (2020) 71-86.

[19] J.A. Muckstadt and M.H. Isaac, An analysis of single item inventory systems with returns. Naval Res. Logistics Q. 28 (1981) $237-254$.

[20] A. Nobari, A.S. Kheirkhah and M. Esmaeili, Considering chain-to-chain competition on environmental and social concerns in a supply chain network design problem. Int. J. Manage. Sci. Eng. Manage. 14 (2019) 33-46.

[21] V.P. Simpson, Optimum solution structure for a repairable inventory problem. Oper. Res. 26 (1978) $270-281$.

[22] S.K. Srivastava, Green supply-chain management: a state-of-the-art literature review. Int. J. Manage. Rev. 9 (2007) 53-80.

[23] K. Takahashi, Y. Doi, D. Hirotani and K. Morikawa, An adaptive pull strategy for remanufacturing systems. J. Intell. Manuf. 25 (2014) 629-645.

[24] M. Thierry, M. Salomon, J. Van Nunen and L. Van Wassenhove, Strategic issues in product recovery management. California Manage. Rev. 37 (1995) 114-136.

[25] E. Van der Laan and M. Salomon, Production planning and inventory control with remanufacturing and disposal. Eur. J. Oper. Res. 102 (1997) 264-278.

[26] E. Van der Laan, R. Dekker, M. Salomon and A. Ridder, An $(s, q)$ inventory model with remanufacturing and disposal. Int. J. Prod. Econ. 46 (1996) 339-350.

[27] E. Van der Laan, R. Dekker and M. Salomon, Product remanufacturing and disposal: a numerical comparison of alternative control strategies. Int. J. Prod. Econ. 45 (1996) 489-498.

[28] E. Van der Laan, M. Salomon and R. Dekker, An investigation of lead-time effects in manufacturing/remanufacturing systems under simple push and pull control strategies. Eur. J. Oper. Res. 115 (1999) 195-214.

[29] Y. Xiong and G. Li, The value of dynamic pricing for cores in remanufacturing with backorders. J. Oper. Res. Soc. 64 (2013) $1314-1326$.

[30] Y. Xiong, G. Li, Y. Zhou, K. Fernandes, R. Harrison and Z. Xiong, Dynamic pricing models for used products in remanufacturing with lost-sales and uncertain quality. Int. J. Prod. Econ. 147 (2014) 678-688.

[31] Y.-C. Zhou and X.-C. Sun, Robust optimal inventory and acquisition effort decisions in a hybrid manufacturing/remanufacturing system. J. Ind. Prod. Eng. 36 (2019) 335-350.

[32] H. Zolfagharinia, M. Hafezi, R.Z. Farahani and B. Fahimnia, A hybrid two-stock inventory control model for a reverse supply chain. Transp. Res. Part E: Logistics Transp. Rev. 67 (2014) 141-161.

\section{Subscribe to Open (S2O) A fair and sustainable open access model}

This journal is currently published in open access under a Subscribe-to-Open model (S2O). S2O is a transformative model that aims to move subscription journals to open access. Open access is the free, immediate, online availability of research articles combined with the rights to use these articles fully in the digital environment. We are thankful to our subscribers and sponsors for making it possible to publish this journal in open access, free of charge for authors.

\section{Please help to maintain this journal in open access!}

Check that your library subscribes to the journal, or make a personal donation to the S2O programme, by contacting subscribers@edpsciences.org

More information, including a list of sponsors and a financial transparency report, available at: https://www. edpsciences.org/en/maths-s2o-programme 